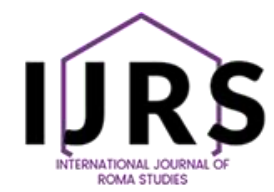

$\underset{\text { Hww.hipatiapress.com }}{\text { Hipatia }}$

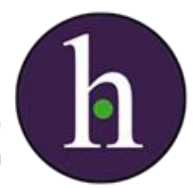

Instructions for authors, subscriptions and further details:

http://ijrs.hipatiapress.com

\title{
Assessing the Impact of Community Centres on Roma Integration: A Study of Eastwood
}

\section{Olga Fuseini ${ }^{1}$}

1) The University of Sheffield, United Kingdom

Date of publication: November $15^{\text {th }}, 2021$

Edition period: November 2021 - March 2022

To cite this article: Fuseini, O. (2021). Assessing the impact of Community Centre on Roma Integration: A study of Eastwood. International Journal of Roma Studies, 3(3), 243-267. doi: 10.17583/ijrs.9141

To link this article: https://doi.org/10.17583/ijrs.9141

\section{PLEASE SCROLL DOWN FOR ARTICLE}

The terms and conditions of use are related to the Open Journal System and to Creative Commons Attribution License (CCAL). 


\title{
Assessing the Impact of Community Centres on Roma Integration: A Study of Eastwood
}

\author{
Olga Fuseini \\ The University of Sheffield
}

\section{Abstract}

During the last 10 years, Roma have become the second largest and the most deprived ethnic minority in Rotherham and thus, the local authority has put Roma integration as a priority in terms of community planning and development. Due to the complexities around Roma integration and the government budget cuts to public spending, the local authorities rely on community centres to fill gaps in improving the Roma integration and their quality of life in the UK. This article aims to assess the impact of a community centre on Roma integration, specifically, focusing on the Eastwood area of Rotherham. The research methods included semistructured interviews of professionals that regularly engage with Roma community and the Roma residents of Eastwood. The case study findings show that the Eastwood community centre plays a vital role in the Roma integration. Some of the main contributing factors include their expertise and the ability to effectively engage with the Roma community. However, this paper only touches upon the issue of Roma integration in the UK, which means that more comprehensive and a larger scale of research is needed to improve the processes of Roma integration and the integration of other communities in similar settings.

Keywords: Roma, Community Centre, Integration, Community Integration Policy 


\section{Evaluación del impacto de los centros comunitarios en la integración de los romaníes: un estudio de Eastwood}

Olga Fuseini

The University of Sheffield

\section{Resumen}

Durante los últimos 10 años, los Gitanos se han convertido en la segunda minoría étnica más grande y más desfavorecida de Rotherham (Reino Unido) y, por lo tanto, la autoridad local ha dado prioridad a la integración de los Gitanos en términos de planificación y desarrollo comunitarios. Debido a las complejidades en torno a la integración de los Gitanos y los recortes presupuestarios del gobierno al gasto público, las autoridades locales confían en los centros comunitarios para llenar los vacíos en la mejora de la integración de los gitanos y su calidad de vida en el Reino Unido. Este artículo tiene como objetivo evaluar el impacto de un centro comunitario en la integración de los romaníes, específicamente, centrándose en el área de Eastwood de Rotherham, Reino Unido. Los métodos de investigación incluyeron entrevistas semiestructuradas de profesionales que se relacionan regularmente con la comunidad Gitana y los residentes romaníes de Eastwood. Los resultados del estudio de caso muestran que el centro comunitario de Eastwood juega un papel vital en la integración de los Gitanos. Algunos de los principales factores que contribuyen incluyen su experiencia y la capacidad de interactuar de manera eficaz con la comunidad romaní. Sin embargo, este documento solo aborda el tema de la integración de los Gitanos en el Reino Unido, lo que significa que se necesita una investigación más exhaustiva y a mayor escala para mejorar los procesos de integración de los Gitanos y la integración de otras comunidades en entornos similares.

Palabras clave: Gitanos, Centro comunitario, Integración, Política de integración comunitaria 

M ainstream literature which deals with dimensions of Roma integration often focuses on the impacts of poor practices of Roma engagement or the negative outcomes of national and local policies which lead to Roma exclusion in accessing services and deprivation. While these are all very important subjects that need to be discussed, there is a gap in the literature that shows a lack of positive examples of the good practices and their impact on Roma integration. Such practices are more likely to be recognised on a local level often shared through the network of professionals directly involved with the Roma community, but lacking the recognition of the national government. However, now, that Roma were included in the Census 2021 as an independent ethnic group (ONS 2018), new research opportunities will arise and generate fresh data to provide a clearer picture of the UK's Roma population.

The content of this paper may serve as a useful tool for the UK government and policymakers when assessing the needs of the Roma population and creating strategic plans to improve their lives, and at the same time decrease pressure on public services (Poppleton, 2013). As an educated Roma woman with years of experience in Roma engagement and as a support worker, I have witnessed several different practices using strategies that slowed down or sped up the processes of Roma integration. Therefore, I believe that it is important to highlight the good work of NonGovernmmental Organisations (NGO) and their impact on neighbourhoods with a large Roma population. The following question is examined: To what extent has the Eastwood Community Centre enhanced the integration of Roma People in Eastwood, UK? In this case study, the term 'integration' was defined as: "The action or process of successfully joining or mixing with a different group of people" (Cambridge Dictionary, 2021:1).

To answer this question, the article will commence by providing a brief background on Roma people and their life in the UK as well as information on community centres. The next part develops a literature review around the concept of integration and introduces the analytic framework used throughout the article. The following section will include the research methodology, the background to the case study and the analysis of findings. This section will also outline the participant's responses to questions around Roma integration in Eastwood and the role of the Eastwood Community 
Centre (ECC) on the Roma integration. The final part of this paper summarises the findings and considers how these might inform our understanding of the role of community centres in the context of a nuanced understanding of integration.

\section{Who are the Roma People?}

The Council of Europe (2021) uses the term 'Roma' (plural) to refer to "Roma, Gypsies, Sinti, Kale, Romanichals, Boyash/Rudari, Balkan Egyptians and Eastern groups 'Dom', 'Lom' and 'Abdal' (The Council of Europe, 2021, cited in EUAFR 2018: 100). Roma people have their own language which shares similarities with northern Indian languages (Matras, 2015). Their origins are still unknown but there is evidence of their gradual migratory routes through Persia, Armenia, the eastern Greek Empire and into Europe (Matras, 2015). Throughout the history, the Roma people have been subjected to prosecutions, slavery and indentured labour (particularly in Romania) right until the late 19th century (Hancock, 2017).

According to the European Union Agency for Fundamental Rights (EUAFR, 2018), Roma people belong to the largest ethnic minority in Europe. Many writings on Roma life and history describe this ethnic group as a 'bohemian' people of 'mysterious' origins with a distinctive way of life and a passion for a music and art which enriched cultures around the world (Matras, 2015; Hancock, 2017). As Loveland \& Popescu (2016) point out, these attributes are overpowered by narratives that put more emphasis on Roma as victims of social exclusion or Roma as villains: a threat to society unwilling to integrate. In both accounts, Roma are presented as a 'social problem' that needs to be solved. The EUAFR 2016 and 2018 found that Roma is not just the largest, but also the most disadvantaged ethnic minority in Europe. They identified 'anti-Gypsyism' (prejudice against Roma/Gypsies) as one of the main factors of Roma discrimination in Europe, specifically in the areas of health, education, housing and employment (EUAFR, $2016 \&$ 2018). The latest available figures show that in Europe, $80 \%$ of Roma remain at risk of poverty and the rates for Roma that are not in education, training or employment increased from $56 \%$ to 63\% between 2016 and 2018 (EUAFR, 2018). 


\section{Roma in the UK}

Since the EU enlargement in 2004 and 2007, the EU migration rate of Roma to the UK has increased significantly and so has the Roma population (ONS, 2014; Migration Yorkshire, 2017). Roma communities are spread across all parts of the UK, but some areas, like South Yorkshire, host a larger Roma number which often occupy the poorest parts of towns and cities (Migration Yorkshire, 2017). The 2011 Census did not include a 'Roma' category in its ethnic minorities list so, the size of the Roma population in the UK was uncertain (Migration Watch 2013; ONS, 2018). However, some NGO research organisations like Migration Watch (2013) and Migration Yorkshire (2017) have estimated that in 2011, there were approximately 300,000 Roma living in the UK. Despite the lack of national data related specifically to the Roma population, the information collected by local authorities, third sector services and NGO research organisations, recorded rising numbers of Roma families with multiple immediate needs related to poverty and deprivation (Migration Yorkshire, 2017; The Star, 2016; Brown, et al., 2016). With over-stretched budgets and scarce resources, local authorities rely on NGOs like charities and community centres to support migrants with such needs and help them to 'successfully' integrate (Gidley \& Mayo, 2021); hence the focus on the role of the local community centre in this article.

\section{Community Centres}

Third sector organisations such as community centres are NGOs that run on funds donated by the government, the public or the private sphere (CCEW, 2004). They are considered a valuable asset, especially in areas with a diverse population, as they help to promote tolerance and community cohesion (Gidley \& Mayo, 2021, Izmir, at al., 2009). The purpose of community centres is to improve the lives of individuals and families by providing a range of direct services and to act as a bridge between the local residents and other service providers (Izmir, at al., 2009). The direct services could be social, educational or advice and charity oriented, and they are generally led by users' needs and basic government guidelines (CCEW, 2004).

Community centres seek to improve social capital, build a stronger society and help to overcome barriers created by circumstances and social 
inequality (Izmir, et al., 2009; Gidley \& Mayo, 2021). Ethnic minorities like Roma migrants in the UK often face many barriers that hinder their integration to society as they present with multiple immediate needs (Brown, et al., 2016). Community centres are then inclined to take a holistic approach when engaging with Roma families which often require working in partnership with other services like health and social care, council services or other third sector organisations like Citizen Advice Bureau (Brown, et al., 2016; CCEW, 2004). Evidence suggests that through such activities, community centres play a positive role in their neighbourhoods (CCEW,2004; Gidley \& Mayo, 2021). This paper is specifically looking at the role of the community centre in relation to ethnic community integration, which focuses on the case of Roma migrants in the UK.

\section{Analytical Framework of Integration}

The analytic framework for this article draws on two main sources. The first source is the official government documents, which shape the inclusion policy that is implemented in public and third sector services like community centres (Home Office, 2019; HM Government 2018). These documents offer a general conceptualisation of integration and set out what is deemed to be 'successful' integration. The second source is Catney at al. (2011) on Diversity and the Complexities of Ethnic Integration in the UK, which provides a deeper understanding of the complexity and diversity of 'ethnic' integration specifically.

\section{What is Integration}

Despite the fact that integration plays an important role in state policies, national projects promoting tolerance and community cohesion, there is no consensus on a universal model or definition of integration (Ager and Strang, 2008; HM Government, 2018). In a socio-political sense, 'integration' is a contested concept because of its widely differing meanings, shaped by multiple dynamic domains and dimensions such as space, place, size, type of integration and social structure (Ager and Strang, 2008; Catney et al., 2011). The UK Government (2018) describes 'integrated communities' as: 
Communities where people, whatever their background, live, work, learn and socialise together, based on shared rights, responsibilities and opportunities. Communities where many religions, cultures and opinions are celebrated, underpinned by a shared set of British values that champion tolerance, freedom and equality of opportunity. A society in which everyone is a potential friend (HM Government, 2018:10)

The UK Government presents integration as a positive and inclusive concept promoting partnership and shared responsibilities between migrants and the host country (HM Government, 2018; Home Office, 2019). However, there are some that view the concept of integration as negative for the way it is used by media, politicians or the general public (Rytter, 2018). This is specifically when the term 'integration' is used in reference to migrants and ethnic minorities portrayed a 'problematic group' that is unwilling to conform (Rytter, 2018). This shows that perceptions of integration play an important role in defining 'successful integration' (Rytter, 2018; Catney, 2011). The government's definition is also quite long and complex and may not be well understood by some participants in this research. Following initial conversations with professionals who work with the Eastwood community, it is for these reasons that I have adopted a simpler and arguably more neutral definition of integration for his paper: "The action or process of successfully joining or mixing with a different group of people" (Cambridge Dictionary, 2021:1).

\section{Assessing Integration}

There is on-going debate on what 'successful' integration looks like and what markers and domains should be considered when accessing integration (Ager \& Strang, 2008) (see Figure 1). Over time these discussions have helped to build a foundation for an integration framework that serves as a tool for policy makers and social science researchers. For example, McLeod (1996) and Stamm and Weis (1986) claim that the 'psychological' domain (e.g., sense of belonging) and 'behavioural' domain (e.g., the level of participation or conformity) should also be included in the discussions of integration. Catney et al., (2011), focus specifically on ethnic integration, arguing that there are several dimensions missing such as 'space' and 
'place', 'ordinariness', 'religion' and 'language'. Finally, the integration framework created by Ager \& Strang (2008) shows development as it touches upon all of the missing components mentioned by McLeod (1996), Stamm and Weis (1986) and Catney et al., (2011). Ager \& Strang (2008) identify four key domains (out of 10) that also serve as the markers and means of 'successful' integration when achieving or accessing the areas of; education, health, employment and housing. Ten years later the integration framework by HM Government (2018) and Home Office (2019) still retains the same foundation and builds on the work by adding new domains as needed (e.g., 'Leisure' and 'Digital skills', see Figure 1.)

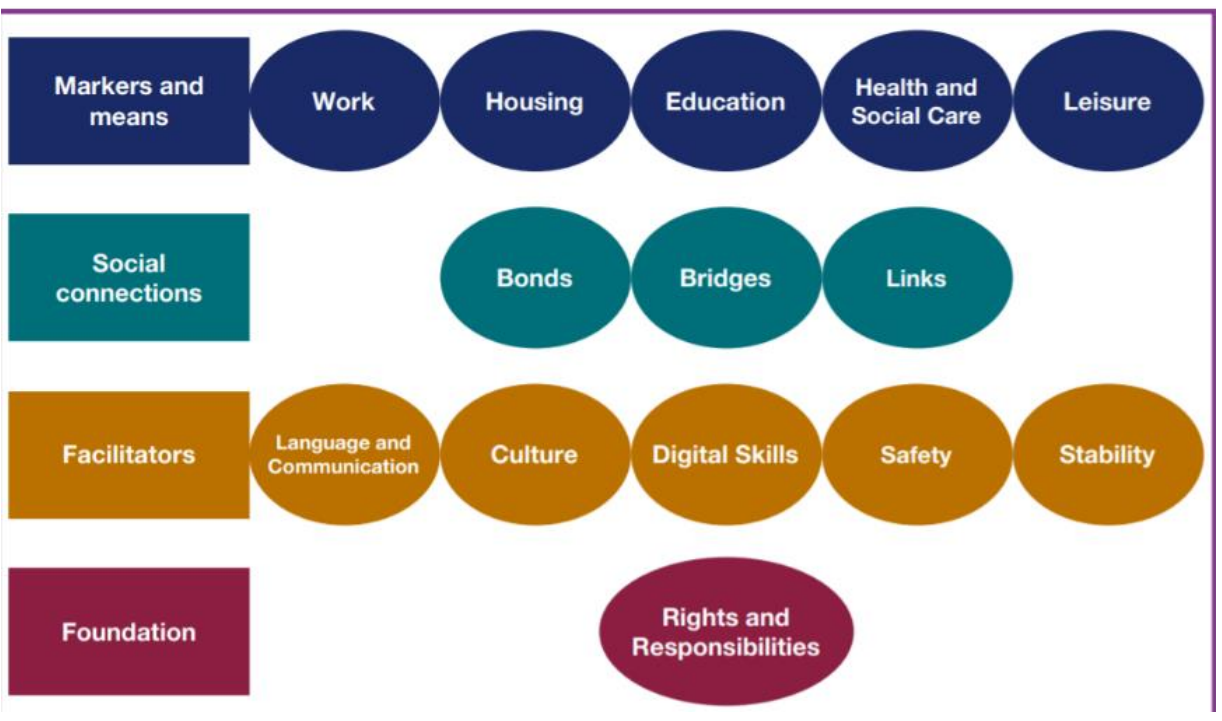

Figure 1. Indicators of Integration Framework Source: Home Office (2019)

\section{Barriers to Successful Community Integration}

Anything that hinders the processes leading to 'successful' integration is recognised as a 'barrier' (Ager \& Strang, 2008). There are many types of barriers that are shaped by various factors within the domains and dimensions of integration (McLeod, 2011). Some barriers arise as a result of 
government policy, such as the 2010 benefits reform and funding cuts to youth services, which hit the most disadvantaged in our society (CCEW,2004; JFR, 2015; The Guardian, 2020). More recently, 'Brexit', and its new immigration rules, bring many challenges not just for EU migrants but also for NGOs and other service providers that are already stretched and underfunded (RSG, 2021:7). Common barriers like racism or anti-Gypsyism are historic problems deeply rooted in a social structure that excludes and segregates ethnic groups on the basis of prejudice (Kende et al., 2020; EUAFR, 2018). Ethnic communities dealing with such problems have a lower chance to successfully integrate into society (Kende et al., 2020). Locally-based community organisations are well placed to identify barriers and create strategies that help to overcome them (HM Government, 2019). In 2018, the UK government deemed the language barrier as the biggest problem for migrant communities. They highlighted that it restricted migrant communities' access to the five core domains of integration (housing, health care, education, employment, leisure) and disrupted their social bonds (HM Government, 2019, Home Office 2018). In this case, community organisations were encouraged to respond by setting up English as a Second Language [ESOL] classes (HM Government, 2018).

\section{Measuring integration}

Measuring the progress of integration is a challenge because of its complex and diverse nature (Home, Office 2019). This means that the speed and progress of integration varies for different groups (Catney, et al., 2011). So, for example, someone with good English would usually find it easier to find a job or create a social bond with English speakers. When measuring success, it is important to set a baseline with realistic goals (e.g., expected national average) against which data can be measured (HM Government, 2018). The UK government uses the Race Disparity Audit (Cabinet Office, 2017) as a tool to identify and measure the gaps and barriers which prevent ethnic minorities from accessing services and, thus, successfully integrating (HM Government 2018). However, if this approach was based on insufficient data, it would lose credibility on the basis of underrepresentation. In this case, a localised qualitative approach is better for monitoring impact because it often involves a small-scale study with the 
possibility of a wider application (Gugerty and Karlan, 2018; Tellis, 1997). The problem of lower validity from insufficient data is solved by collecting localised primary data (e. g. from interviews) from a small group of participants which represents wider society and provides a specific and unique insight to the researched subject (Gugerty and Karlan, 2018; Tellis, 1997). This is the approach taken here.

\section{Methodology}

This research adopts a single-case study approach. However, a multiple-case study would also be suitable here as it allows the researcher to analyse each case separately in various settings while searching for patterns, similarities and differences and thus, increasing the validity of this research (Baxter and Jack, 2008). On the other hand, the multiple-case study may be too complex for one researcher and the large amont of data could prevent deeper knowledge (Baxter and Jack, 2008:6). Therefore, the single-case study remains the most appropriate approach for this research question. There are also advantages for me in choosing this case which I wil outline in this section.

Crowe, et al., (2011:1) describe a 'case study' as "a qualitative research approach that is used to generate an in-depth, multifaceted understanding of complex issues in its real-life context". This approach has its strengths but also its weaknesses. One of the advantages of the case study design is that it answers the research question in such a way that the experimental approach cannot (Unluer, 2012; Crowe et al., 2011). This is because this design applies qualitative methods such as interviews, which bring clarity and unique insight into complex issues (Unluer, 2012). Another advantage is that a single-case study is more efficient in terms of time and money as its main focus is on a single case rather than multiple cases (Gaille, 2018; Tellis, 1997). The weaknesses of this approach lie in the risk of collecting a large amount data which will take a long time to process and analysis (Gaille, 2018). The single-case study approach is often criticised for not abiding by the strict scientific rules that affect research validity and also that the research findings are not transferable to other types of settings (Crowe, et al., 2011; Unluer, 2012). However, according to Crowe et al., (ibid), the problem of validity could be addressed by complete transparency of the 
whole research process (e.g., the reasons behind the research, the way the data was collected, how the participants were selected, potential risk of bias, the researcher's background, etc.). Furthermore, Crowe et al. (ibid) and Unluer (2012) add that the issue of the problem of lack of research discipline is justified by the accumulation of unique data, which would not be possible to collect from a more rigid approach. The case study chosen for this article is the Eastwood area of Rotherham. Eastwood is the most deprived area of Rotherham with a high concentration of Roma population that often face multiple barriers to integration (RMBC, 2019). In 2016 and 2019, The Rotherham Metropolitan Borough Council (RMBC) identified the Roma integration as one of the key areas of improvement in which the Eastwood community centre (ECC) played an important role (RMBC, 2016; RMBC, 2019). My past work experience as a community development worker in Eastwood, have enabled me to observe the positive impacts of ECC work on numerous Roma individuals and families living in this area. Therefore, I have developed a strong interest to study these impacts, highlight the good practices of ECC and apply them into other similar settings across the UK.

\section{Positionaity}

My Czech Roma background allows me to have unique access to a community that is normally closed to others (Matras, 2015). I grew up in a traditional Roma home with Christian values where both parents spoke Roma, Czech and Slovak. My Roma heritage and understanding of the Roma way of life, have helped me to be accepted in the Roma community but also to conduct the interviews in such a way that I was able to gain deeper insight into the complex and highly charged topic such as Roma integration. Trust is an essential element to successful Roma engagement (Brown, 2016). Due to historic abuse, Roma have developed a mistrustful relationship with non-Roma professionals: especially with those who works for a local authority (Brown, 2016; Matras, 2015). Furthermore, between 2011 to 2017 I was employed as a community development worker by the Clifton Learning Partnership [CLP] which is based in Eastwood Community Centre [ECC]. This connection has helped me to get a unique access to contacts and reports specific to Eastwood area of Rotherham. I am aware, 


\section{Fuseini - Impact of Community Centres on Roma in Eastwood}

however, that these 'advantages' could, in another sense, be viewed as disadvantages by some, as I may be accused to have a strong bias and lack of objectivity in the research process compared to a non-Roma researcher (Unluer, 2012). Nevertheless, I plan to counter any bias possibility by putting in place measures like regular checks from my supervisor; asking the participants to review my results; including alternative perspectives and using multiple data sources (Unluer, 2012; Baxter \& Jack, 2008).

The methods used in this research include individual semi-structured interviews and examination of official documents and reports produced by the ECC (Eastwood Community Centre) and the RMBC (Rotherham Metropolitan Borough Council). The main reason for this approach is the serious lack of data on the Roma population in the UK. These methods enabled me to collect unique contextual information that are unlikely to be found in any other academic or officially available source.

To get a wider perspective on Roma integration, participants were selected from various backgrounds but with a professional or personal connection to Eastwood. Here are the three generic profiles that you will find within the project, however I will remain and retain what might appear to be disjointed for the purpose of confidentiality which links to the ongoing trust-based relationship that I have with the interviewees:

- Eight ECC employees (of which one is Roma) in various job roles such as director, centre manager, funding manager, family support worker and community development worker.

- Four RMBC employees (of which one recently retired) holding the positions of project co-ordinator, councillor, street pride worker and a police community support officer [PCSO]

- Eight Czech and Slovak Roma residents (ranging from 32 to 54 years old) from various socio-economic backgrounds who live in different parts of Eastwood. Their length of residency ranged between 2 and 16 years with an average of 5 years.

Participants were selected in the following ways: I contacted the ECC workers who then helped me to get in touch with the most suitable RMBC employees. The ECC also helped me engage two Eastwood residents who 
then recommended their friends and neighbours, some of whom took part in my research.

The professionals (the RMBC and the ECC employees) and the Eastwood residents (ERs) were interviewed using two separate sets of thematic questions focusing on four thematic areas: 1. The Roma integration in Eastwood; 2. The barriers to Roma Integration in Eastwood; 3. The impact of the ECC on Roma integration; 4. The way forward. There were eight and ten thematic questions in total with sub-questions that were set or added later, depending on how the interview developed. The interviews were conducted online using Zoom or WhatsApp video calls. Prior to that all participants were provided with relevant research information and their consent was recorded in a verbal or written form. The consent form and the participant information sheet were verbally translated for all the Eastwood residents and their interviews were conducted in their preferred language (Czech, Slovak or Roma). Participants were happy to answer all of the questions asked and many provided additional comments when given the opportunity at the end of the interview.

\section{Challenges}

Covid 19 restrictions hindered the recruitment process of Eastwood residents, resulting in fewer initial participants. As the ECC was relied upon to recruit the first three participants, this may have affected the objectivity and the credibility of this paper. Furthermore, the lockdown rules forced me to conduct the interviews online. This hindered my access to the most vulnerable Roma residents of Eastwood, that come from the poorest parts of Slovakia, who did not have the digital equipment or skills to participate in this study. The pilot interview revealed flaws in one or both sets of interview questions where some questions were found irrelevant or repetitive. This problem was solved by minor corrections which resulted in significant improvement in the next interview. Another challenge was to find a suitable definition of integration for one of my interview questions which was not too complicated and which included cultural and behavioural aspects of community cohesion. The first two interviews revealed that the definition I had was too narrow and simplistic, so I replaced it for a more fitting definition that was also easy to explain to non-English speaking participants. 


\section{Case Study}

The ECC is a building from which the 'Clifton Learning Partnership' (CLP) operates. This is a company and charity organisation that has operated in Eastwood since 2011 (CLP, 2021). Initially known as an 'Education Action Zone', this charity was built upon 12 years of experience working with local schools their families (CLP, 2021). Their drive is the vision of "a strong cohesive local community which is safe, healthy, and skilled, in which people contribute and participate" (CLP, 2021,'Our Vision'). To achieve this, the ECC delivers numerous activities aimed at all Eastwood residents (often in partnership with other organisations) and provides opportunities for growth and improvement (CLP, 2021). According to the CLP's records, the ECC sees up to 4000 individuals per year (CLP, 2021). What sets this charity apart from others is that it has a sister company 'Clifton EMAG Ltd', which puts all of its profit into the CLP's bank account: this makes it selfsufficient and less dependent on government funds (CLP, 2021). The ECC is based in the most deprived area of Eastwood known as the 'Eastwood Village' (see figure 2.) (RMBC, 2016). Eastwood is a multi-ethnic neighbourhood in Rotherham with mainly high density and poor-quality terraced housing (RMBC, 2019; RMBC, 2016).

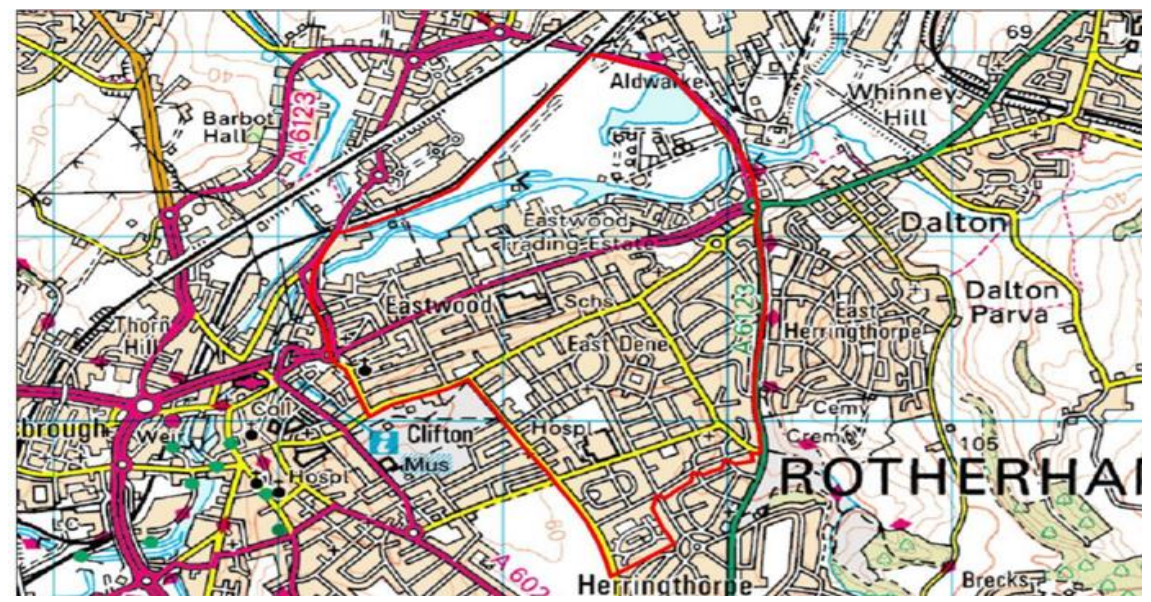

Figure 2. The Rotherham East Ward Profile: RMBC (2019) 
It has a large Roma population of Czech and Slovak nationality (Migration Yorkshire, 2017; Appendix 1). It was estimated that between 2012 and 2015, the size of the Roma population in Rotherham doubled (from 2000-4000), which meant that Roma became the second largest ethnic group after Pakistanis (Migration Yorkshire, 2017).

Key:

ECC (1-6) = Employee of the Eastwood Community Centre

RMBC (1-4) = Employee of the Rotherham Metropolitan Borough Council ER (1-8) = Eastwood Resident

\section{Discussing the Findings}

This paper aimed to find out to what extent the ECC has enhanced the integration of Roma People in Eastwood. To assess the impact of the community centre on the Roma integration, the following section will reflect on interview data in relation to the analytic framework.

Looking at the perception of integration, the professionals' views of successful/integration were similar to the government's lengthy definition in HM Government $(2018, \mathrm{p} 1)$. They also agreed with the government's 'twoway stream' theory which suggests that successful integration requires the participation of both, government and the migrants. This was specifically evident in professional's responses on barriers of Integration, where they identified barriers that were both, external and internal to Roma community. For example, the participant ECC6 expressed her frustration with an external barrier related to funders who expect unrealistic outcomes from a community with so many complex needs. So, in practice, the funder would offer six months funding for job searching activities that would eventually lead to employment. However, ECC6 argued that this approach would not work for most of their Roma clients, as it doesn't consider their literacy levels, language barriers or the immediate stresses that does not allow the 'breathing space' for learning. ECC6 suggested that it is important that funders get Roma awareness training. 
The Eastwood residents - ERs (including the Roma professional ECC4) chose to keep conceptually closer to the simplified definition in Cambridge dictionary (2021) with emphasis on being a law-abiding citizen and accepted member of society. The ER2 said:

Yeah, I personally think that we have adapted. We don't cause any problems, kids go to school and we go to work...but that is because we are different, we are Czech, ...we have been already integrated in Czech. So, if you grew up in slums, living like five centuries ago in hand-made huts and dirt and muddy floors, it is no surprise that you will need more help to integrate....

The statement above shows two important points. Firstly, ER2's view of integration, shares similarities with government's definition of integration. And secondly, it suggests a hierarchical order within the Roma community, based on socio-economic status.

However, the Roma participants did not share the government's 'two-way stream' approach to integration, instead, they took a full responsibility for their own integration and thus, blaming the Roma community when things went wrong. The ECC4 (Roma professional) said:

Many Roma parents have low aspirations for their kids. They can discourage them from pursuing higher education. This is worst for girls. We see many Roma girls finish the secondary school and then have babies so early. I am Roma too, I know it was always in our culture, but this has to change now that we are in the UK where we have more opportunities.

ER2 said: "I have come to know that some Roma that lived here even for 10 years or longer, kept the same slum like mentality and bad habits up to today, they don't want to change!"

In terms of understanding the term 'integration', seven out of eight Roma participants said they understood what integration means, because that's what they were always penalised for by the Czech and Slovak media and politicians. The ER5 said: "They (the Czech and Slovak media and 
politicians) always told us that we refuse to integrate... but how are we supposed to do that when they hate us, ...when they don't accept us?"

Rytter (2018) makes similar point when he explains that successful integration requires participation of both, the community and the state.

The government documents present a very broad definition of ethnic minorities which suggests that the Roma community is homogeneous. However, the ERs interviews suggested that Roma differentiate themselves on the basis of their socio-economic backgrounds. This observation was largely missed by the RMBC professionals compared to the ECC professionals, who were more knowledgeable in this area due to their Roma engagement experience. For example, during the interview, the ECC1 showed deeper understanding of the Roma community structure. The ECC1 said: "...I have learned that Roma people come from different socioeconomic backgrounds. The most vulnerable families are often those newly arrived to the country coming from extreme poverty in Slovakia..."

When looking at the evaluation of the Roma integration, all professionals agreed with government documents that measuring integration is complex because everyone integrates differently. For example, the RMBC 1 said:

I think yes, but in some areas more than others.... Integration is not something that happens overnight, it takes a generation or two... Some people take slower to integrate than others... But we do want people to retain some of their own culture, don't we?

HM Government (2018) suggests setting a realistic baseline against which the data are measured to determine their level of integration. However, if the Roma population is excluded from the database, then the baseline is not sufficient enough as it doesn't represent all groups. To put this theory in practice, the ECC6 complained about the funders expecting the same outcomes from the Roma community as they would from the majority of English population. ECC6 said: “...they don't consider their (the Roma) literacy levels, their language skills or the immediate stresses that puts pressure on whole family... it is important that funders get Roma awareness training." 
Furthermore, the ECC2 expressed her frustration the current benefit rules that "...seem to ignore Roma's immediate needs". For example, the ER4 said:

My wife has lost a job because she had to attend one of the ESOL classes ordained by the Universal Credit. The boss called her unexpectantly to come to work on Friday, but that's when she had her ESOL class... she lost her job because she had to choose between earning a good wage an keeping her Uni Credit.

Many Roma people with low English skills have insecure jobs with irregular 'zero-hours' contracts (Brown, 2016) which clashes with their mandatory ESOL classes. Due to the digital poverty, educational needs and language barriers, some Roma fail to log into their Universal Credit account and communicate with their work coach (Graham, 2019)

When we examined the barriers of Roma integration in Eastwood, all professionals identified the lack of English skills as their primary hindrance in accessing jobs and services. The government documents also agreed with this statement by saying that speaking English was on top of the list of indicators showing a successful integration (HM Government, 2018, Home Office 2019). Although the Professionals agreed with this statement, the ECC employees highlighted additional challenges that Roma face when learning to speak English. ECC5 said: “... many Slovakian Roma speak only Romani language at home which has a limited vocabulary and this weakens their Slovakian language... this makes it so much harder to learn another language."

The ECC employees also highlighted the impact of a poverty related immediate stresses that force the Roma families into a 'survival mode' in which finding a job is more important than attending the ESOL classes. Therefore, any strategic plans for Roma integration in Eastwood that puts more effort into tackling the language barriers rather than poverty and deprivation, may need to be reconsidered.

Furthermore, the professionals and the ERs have identified additional barriers to Roma integration such as: poverty, deprivation in all areas of integration, racial discrimination, insufficient funding, low aspirations, lack of Roma awareness in settings and the negative narratives promoted by media and politicians. 
When measuring the progress of the Roma integration, the professionals and the ERs have mostly agreed that in the last ten years, the Roma community in Eastwood exhibited slow but visible progress in the following areas of integration: community cohesion; trust in authorities; participation in activities that improved their lives and their environment; being settled in Eastwood for a longer period of time; showing a better understanding of their rights; having higher aspirations for their children and encourage higher education. The ECC1 said:

...The children are attending schools and as a result, we can see some improvement in parent's aspirations for these children. People have got jobs and they stay in Eastwood. We even see some families come back to Eastwood after they left years ago, but there is still a long way to go.

A settled Roma community may be a rare image to some, but studies show that the nomadic life of the Roma people in the UK is not a voluntary action, but it is a result of life circumstances that were forced upon them such as loss of job, social exclusion or high living costs (Brown, 2016; Migration Yorkshire 2017). The ECC4 worker suggest that having a Roma community that is settled is a sign of progress in their integration.

The Eastwood residents echo the views of professionals and some pointed out how they changed their attitude towards the non-Roma residents from 'hard' to 'softer'. For example, the ER4 said:

I had to change the way I live. In Slovakia we live a hard life which will make you 'hard minded' person in the sense that you always have to be prepared for the worst and bad attitude from 'Gadze' (nonRoma). But in the UK, I have become soft and I left that tough attitude behind $\ldots$ because I feel free here and accepted.

The interviews have also revealed that the Roma residents that come from upper socio-economic background disassociate themselves from those coming from slums when it comes to evaluation of their own integration (all questioned ERs except one never lived in slums). The ERs believed that unlike the 'others' (referring to the poor Roma from slums), they are 
successfully integrated because they were already integrated in Czech or Slovakia.

So, what role does the Eastwood Community Centre (ECC) play in Roma Integration. According to participant's responses, the ECC is an essential part of Eastwood because it helps to improve and accelerate the progress of Roma integration. All participants believed that without the ECC, the Roma community in Eastwood would be more deprived and unstable. RMBC 1 said: "The work that the ECC does is invaluable. They give people voice through steering groups and different events and by doing this, empower the community."

The ECC provides a wide range of activities and various interventions that help to fill the gaps that other sector organisations have failed to tackle. By working in partnership, the ECC often serves as a 'bridge' between the agencies and the Roma community which has a positive impact on Roma's trust in local authorities and provides. ECC3 said:

... The ECC helps in a three-way approach. We give advice and support; we work with children and youth because we know that they are the future generation of Eastwood ... and we help to strengthen the community by bringing people from different backgrounds together.

\section{ER8 said:}

I came here 15 years ago so I know how bad Eastwood was before. The change for better started since the community centre began their work in Eastwood. The community centre worked with the difficult families and they taught them to change their bad habits they brought form the slums in Slovakia...

The ECC worked in partnership with RMBC to help to tackle housing issues often linked to landlord exploitation. This gave them an opportunity to access people's homes and offer their advice and support. The presence of the Roma workers instantly broke any barriers to trust, and so, it was easier to talk to families about some difficult issues like hygiene or nuisance.

To further improve Roma integration, the professionals' recommendation is to promote Roma awareness training to Eastwood professionals and funders investing in community development work and ethnic integration. 
In terms of the future, everyone interviewed placed their hope into the next two generations that would bring them closer to successful integration. ER7 said: "Wait another 20 years, Roma will own their houses and they will run their own businesses!"

\section{Conclusion}

This article has sought to assess the impact of the Eastwood community centre on Roma integration in Eastwood. As a result of a demographic change in Rotherham, the local authorities have increased their attention on Roma integration. Their focus is specifically aimed at the area of Eastwood which has the highest concentration of Roma migrants predominantly from Czech and Slovakia. Most of the Roma migrants went to the Eastwood area are from a deprived background which made their integration complex. Due to the lack of expertise and mistrust of the Roma community, the Rotherham authorities needed the local community centres to fill the gaps in Roma engagement and help them to successfully integrate.

The methodology of this paper adopted a single-case study approach which has its strengths and weaknesses. My positionality as a Czech Roma researcher could have been classed as a biased but through this place within the community enabled me to have unique access to the Roma community, and to gain a deeper understanding of the issues concerning Roma integration.

The assessment of a Roma integration drew on the analysis framed by the literature on integration and on the interviews involving the RMBC and the ECC professionals and the Eastwood Roma residents. Due to the COVID 19, the semi-structured interviews were restricted to online communication which had an impact on this research. The findings of this research have shown that the ECC's role in Eastwood Roma integration has played a vital role in the integration of the Roma people in the area. It helps to communicate and apply the UK's principles and values that are based on the government's definition of community integration. Due to its position in the community (social and geographical), and its expertise on Roma engagement, the ECC is best placed to identify and tackle the external and internal barriers to Roma integration in Eastwood. Furthermore, the ECC's partnership with other organisations provides a wider range of support and opportunities for the Roma community and at the same time, improves 
Roma's trust in other sector organisations. The case study shows that the work of the ECC empowers the Roma community to better their lives and thus, enables a successfully integration. However, while evidence shows that the Roma people are progressing in their integration the process is slow. For Roma and professionals, the way forward is to equip the younger generation to tackle their barriers to integration and to educate the professionals and funders on Roma history and culture. As such, this paper recommends further research on this subject to attract greater attention of the government bodies and policymakers to allocate more funding for improving the Roma integration in the UK and to set up facilities like the Eastwood Community Centre in similar settings.

\section{Acknowledgment}

First, I would like to thank my personal tutor Professor Ian Bache for his relentless support throughout the whole process of writing this research investigation. I would also like to thank all participants for their honest contributions and for giving up their precious time to take part in this study. And finally, a special thanks to my dear CLP family in Eastwood Community Centre. Their hard work and dedication to support the Roma families in Eastwood have inspired me to write this article and without them, this research would not have been possible. Eastwood is blessed to have you!

\section{References}

Ager, A., \& Strang, A. (2008). Understanding Integration: A Conceptual Framework. Journal Of Refugee Studies, 21(2), 166-191. https://doi.org/10.1093/jrs/fen016

Baxter, P., \& Jack, S. (2015). Qualitative Case Study Methodology: Study Design and Implementation for Novice Researchers. The Qualitative Report. https://doi.org/10.46743/2160-3715/2008.1573

Brown, P., Allen, D., Czureja, S., Dinu, L., Glowacky, S., et al. (2016). Supporting Roma Voices. University of Salford. http://usir.salford.ac.uk/id/eprint/44112/ 
Cabinet Office. (2017). Race Disparity Audit: Summary Findings from the Ethnicity Facts and Figures website.

https://assets.publishing.service.gov.uk/government/uploads/system/ uploads/attachment_data/file/686071/Revised_RDA_report_March_ 2018.pdf

Cambridge Dictionary. (2021). Integration.

https://dictionary.cambridge.org/dictionary/english/integration

Carey, M. (2013). The social work dissertation [electronic resource]: using small-scale qualitative methodology.

https://www.worldcat.org/title/social-work-dissertation-using-smallscale-qualitative-methodology/oclc/609856736.

Catney, G., Finney, N., \& Twigg, L. (2011). Diversity and the Complexities of Ethnic Integration in the UK: Guest Editors' Introduction. Journal Of Intercultural Studies, 32(2), 107-114.

https://doi.org/10.1080/07256868.2011.547171

CCEW - Charity Commission for England \& Wales. (2004). RS 9a-Village Halls and Community Centres.

https://assets.publishing.service.gov.uk/government/uploads/system/ uploads/attachment_data/file/317722/rs9atext.pdf

CLP- Clifton Learning Partnership. (2021). It Takes a Community to Rase a Child. http://www.clifton-partnership.org.uk/about-us.asp

Connelly, S. (2019). Evaluation of Rotherham's Controlling Migration

Fund Programme. Department of Urban Studies \& Planning,

University of Sheffield.

file:///C:/Users/admin/Downloads/RMBC\%20CMF\%20final\%20rep ort\%20(exec\%20summary)\%20(2).pdf [Accessed 7 February 2021].

Council of Europe. (2021). Roma and Travellers.

https://www.coe.int/en/web/roma-and-travellers

Crompton, M., Policy \& Partnerships, RMBC. (2016). Indices of

Deprivation 2015.

http://www.rotherhamccg.nhs.uk/Downloads/Governing\%20Body\%2 OPapers/March\%202016/Enc\%206\%20-

\%20Indices\%20of\%20Deprivation\%202015\%20CCG.pdf

Crowe, S., Cresswell, K., Robertson, A., Huby, G., Avery, A., \& Sheikh, A.

(2011). The case study approach. BMC Medical Research

Methodology, 11(1). https://doi.org/10.1186/1471-2288-11-100 
EUAFR - European Union Agency for Fundamental Rights. (2016). Second Europe Union Minorities and Discrimination Survey: Roma Selected Findings. https://www.gitanos.org/upload/40/13/fra-2016-euminorities-survey-roma-selected-findings_en.pdf

EUAFR - European Union Agency for Fundamental Rights. (2018). Fundamental Rights Report: Roma Integration. (Section 5). https://fra.europa.eu/sites/default/files/fra_uploads/fra-2018fundamental-rights-report-2018_en.pdf

Gaile, B., (2018). 12 Case Study Method Advantages and Disadvantages. https://brandongaille.com/12-case-study-method-advantages-anddisadvantages/

Gidley, B., \& Mayo, M. (2021). Community engagement and community cohesion. Academia.edu. Retrieved 8 November 2021, from https://www.academia.edu/3782305/Community_engagement_and_commu nity_cohesion

Gugerty, M. K., \& Karlan, D. (2018). Ten Reasons Not to Measure Impactand What to Do Instead.

https://educationnorthwest.org/sites/default/files/ten-reasons-not-tomeasure-impact.pdf

Graham, M. (2019). The shocking digital divide that punishes Universal Credit claimants. https://tfn.scot/news/the-shocking-digital-dividethe-punishes-universal-credit-claimants

Hancock, I. (2017). We are the Roma People: Amen Sam e Rromane Dzene, ( $\left.2^{\text {nd }} \mathrm{ed}\right)$. University of Hertfordshire Press.

HM Government (2018). Integrated Communities Strategy Green Paper. https://assets.publishing.service.gov.uk/government/uploads/system/ uploads/attachment_data/file/696993/Integrated_Communities_Strate gy.pdf

Home Office (2019). Home Office Indicators of Integration Framework. Third edition.

https://assets.publishing.service.gov.uk/government/uploads/system/ uploads/attachment_data/file/835573/home-office-indicators-ofintegration-framework-2019-horr109.pdf

Izmir, G., et al. (2009). Neighbourhood and Community Centres: results for children, families and communities. 
http://citeseerx.ist.psu.edu/viewdoc/download?doi=10.1.1.205.4403\& rep=rep $1 \&$ type $=$ pdf

JRF. (2015). The Cost of the Cuts: The Impact on Local Government and Poorer Communities.

https://www.jrf.org.uk/sites/default/files/jrf/migrated/files/SummaryFinal.pdf

Kende, A., Hadarics, M., Bigazzi, S., Boza, M., Kunst, J., \& Lantos, N. et al. (2020). The last acceptable prejudice in Europe? Anti-Gypsyism as the obstacle to Roma inclusion. Group Processes \& Intergroup Relations, 24(3), 388-410.

https://doi.org/10.1177/1368430220907701

Loveland, M., \& Popescu, D. (2016). The Gypsy Threat Narrative.

Humanity \& Society, 40(3), 329-352.

https://doi.org/10.1177/0160597615601715

Matras, Y., 2015. Transnational policy and 'authenticity' discourses on Romani language and identity. Language in society, 44(3), pp.295316.

Mcleod, J., Daily, K., Guo, Z., Eveland, W., Bayer, J., Yang, S., \& Wang, H. (1996). Community Integration, Local Media Use, and

Democratic Processes. Communication Research, 23(2), 179-209. https://doi.org/10.1177/009365096023002002

Migration Watch (2013). EU and the Roma.

https://www.migrationwatchuk.org/briefing-paper/312/eu-and-theroma

Migration Yorkshire. (2017). Roma in South Yorkshire; Mapping services and local priorities.

https://www.migrationyorkshire.org.uk/userfiles/file/projects/romasyorks/syr-3-roma-in-sy-mapping-2017.pdf

Migration Yorkshire. (2018). National Roma Network: Development, Learning and Action.

http://www.migrationyorkshire.org.uk/userfiles/file/publications/MY -finalNRNreport-Oct2018.pdf.

NCVO- National Council for Voluntary Organisations. (2005). Civil Renewal and Active Citizenship: A Guide to Debate. https://cpb-euw2.wpmucdn.com/blogs.lincoln.ac.uk/dist/5/1429/files/2017/01/civil _renewal_active_citizenship.pdf. 
266 Fuseini - Impact of Community Centres on Roma in Eastwood

ONS- Office for National Statistics. (2012). Ethnicity and National Identity in England and Wales: 2011.

https://www.ons.gov.uk/peoplepopulationandcommunity/culturaliden tity/ethnicity/articles/ethnicityandnationalidentityinenglandandwales/ 2012-12-11

ONS- Office for National Statistics. (2014). Migration Statistics Quarterly Report, November 2014.

http://www.ons.gov.uk/ons/rel/migration1/migration-statisticsquarterlyreport/november-2014/stb-msqr-nov-2014.html

ONS- Office for National Statistics. (2018). Inclusion of Roma in the 2021 census.https://www.ons.gov.uk/aboutus/transparencyandgovernance/ freedomofinformationfoi/inclusionofromainthe2021census

Poppleton, S., Hitchcock, K., Lymperopoulou, K., Simmons, J., Gillespie, R. (2013). Social and Public Service Impacts of International Migration at the Local Level Research Report 72. https://assets.publishing.service.gov.uk/government/uploads/system/ uploads/attachment_data/file/210324/horr72.pdf

RMBC - Rotherham Metropolitan Borough Council (2019). Rotherham East Ward Profile 2019.

https://www.rotherham.gov.uk/downloads/file/608/rotherham-eastward-profile

RMBC-Rotherham Metropolitan Borough Council. (2021). Selective Licensing. https://www.rotherham.gov.uk/private-housing/landlordlicensing-1st-may-2020/1

RMBC- Rotherham Metropolitan Borough Council. (2016). Pen Portrait: Eastwood Village and Clifton Learning Partnership 2016

RSG- Roma Support Group (2021). Engaging with the Roma community on the EU Settlement Scheme: Toolkit for local authorities and community organisations. https://www.gypsy-traveller.org/wpcontent/uploads/2021/01/RSG-Toolkit-Roma-EUSS-outreach-forLAs.pdf

Rytter, M. (2018). Writing against Integration: Danish Imaginaries of Culture, Race and Belonging. Ethnos. https://doi.org/10.1080/00141844.2018.1458745 
Silver, H., \& Danielowski, L. (2019). Fighting Housing Discrimination in Europe. Housing Policy Debate, 29(5), 714-735. https://doi.org/10.1080/10511482.2018.1524443

Stamm K., \& Weis R. (1986). The Newspaper and Community Integration: A Study of Ties to a Local Church Community. Communication Research. 1986;13(1):125-137. doi:10.1177/009365028601300107 Tellis, W. (1997). Application of a Case Study Methodology. The Qualitative Report. https://doi.org/10.46743/2160-3715/1995.2015 The Guardian. (2020). Youth services suffer 70\% funding cut in less than a decade. https://www.theguardian.com/society/2020/jan/20/youthservices-suffer-70-funding-cut-in-less-than-a-decade

The Star. (2016). The pressure on schools is evident - Huge increase in Sheffield's Roma population highlighted in government report. https://www.thestar.co.uk/news/pressure-schools-evident-hugeincrease-sheffields-roma-population-highlighted-government-report451928

The Migration Observatory (2020). Policy Primer: Integration.

https://migrationobservatory.ox.ac.uk/resources/primers/policyprimer-integration/

Unluer, S. (2012). Being an Insider Researcher While Conducting Case Study Research. The Qualitative Report. Volume 17, Article 58, 114. http://www.nova.edu/ssss/QR/QR17/unluer

Olga Fuseini is a Roma activist and a BA Graduate in Politics and Sociology at University of Sheffield.

Contact address: olgafuseini@yahoo.com 